\title{
Thermal properties of vitrified llw hospital waste incineration ash
}

\author{
Malgorzata Ciecinska $\cdot$ Pawel Stoch • \\ Agata Stoch
}

Received: 31 July 2013/ Accepted: 5 November 2013/Published online: 10 December 2013

(C) The Author(s) 2013. This article is published with open access at Springerlink.com

\begin{abstract}
The low level nuclear waste (LLW) resulting from the use of radioactive isotopes in medicine, industry, laboratories, and other purposes can be immobilized by vitrification, using methods applied in the nuclear power industry. Borosilicate glass is providing the very suitable medium for the majority of the species present in these wastes. Management of LLW waste begins with combustion reducing their amount. The paper presents the results of model studies of vitrification of hospital waste by incorporating it into the composition of boro-aluminosilicate glass, similar to those used in nuclear power industry. The proposed borosilicate waste glass composition was: $\mathrm{SiO}_{2}-56.0, \mathrm{~B}_{2} \mathrm{O}_{3}-15.0, \mathrm{Na}_{2} \mathrm{O}-21.0$, and $\mathrm{Al}_{2} \mathrm{O}_{3}-8.0$ (mass \%). The ashes were mixed in different amount with the glass frit and then remelted to obtain homogenous melt which was vitrified. The influence of the main ash components on the thermal properties of the vitrified waste was studied using DSC and heating microscopy methods. The glass transformation, crystallization and melting temperatures, and Hruby glass stability against crystallization parameter were determined. The correlations between $\Delta C_{\mathrm{p}}$, $T_{\mathrm{g}}$, and $K_{\mathrm{H}}$ were observed and discussed.
\end{abstract}

Keywords LLW waste - Thermal properties · Borosilicate glass $\cdot$ Thermal stability

M. Ciecinska $\cdot$ P. Stoch $(\bowtie)$

Faculty of Material Science and Ceramics, AGH-University of Science and Technology, Mickiewicza 30 ave, 30-059 Krakow, Poland

e-mail: pstoch@agh.edu.pl

A. Stoch

Krakow Division, Institute of Electron Technology, Zablocie 39, 30-701 Krakow, Poland

\section{Introduction}

High level radioactive wastes from both the nuclear power industry and military nuclear programs are currently immobilized by vitrification. Borosilicate glass is providing the very suitable medium for the majority of species present in these wastes [1, 2]. It prevents leaching of radio nuclides by water-an immobilization effect. Environment protection and increase of disposal cost make that vitrification of the low level nuclear waste (LLW) lately is also finding favor [3].

The LLW resulting from the use of radioactive isotopes in medicine, industry, laboratories, and other purposes can be immobilized by vitrification. Immobilization of such waste begins with combustion reducing their amount. According to [4] paper, PCV, and cotton combustion ash containing radio isotopes are suitable for vitrification and ceramization by incorporating it into the composition of boro-aluminosilicate glass, similar to those used in nuclear power industry. The ash is mixed with glass powder and sintered or remelted at $1100-1300{ }^{\circ} \mathrm{C}[4,5]$.

The most durable matrix for waste vitrification would be pure silicate glass, but melting temperature of this glass is too high. Therefore glass composition is a compromise between glass durability and economics. As the primary choice of material for the immobilization of nuclear waste have become borosilicate glasses. They are characterized by a good glass-forming ability, chemical durability, thermal stability, and ability to incorporate many different kinds of waste elements. Among them the most frequently used are sodium borosilicate glasses with addition of other oxides like alumina, calcia and so on [1,2].

The paper presents results of the studies of thermal properties of vitrified ash from hospital waste incineration plant with a borosilicate glass. 
Table 1 Chemical composition of the hospital waste incineration ash (HWA), the base borosilicate glass (BS) and the vitrified products (BS10W, BS20W, BS30W, BS40W and BS50W)/mass \%

\begin{tabular}{|c|c|c|c|c|c|c|c|}
\hline Oxide & HWA/mass $\%$ & BS/mass \% & BS10W/mass $\%$ & BS20W/mass \% & BS30W/mass \% & BS40W/mass \% & BS50W/mass $\%$ \\
\hline $\mathrm{SiO}_{2}$ & 22.2 & 56.0 & 52.6 & 49.2 & 45.9 & 42.5 & 39.1 \\
\hline $\mathrm{B}_{2} \mathrm{O}_{3}$ & & 15.0 & 13.5 & 12 & 10.5 & 9 & 7.5 \\
\hline $\mathrm{Al}_{2} \mathrm{O}_{3}$ & 13.5 & 8.0 & 8.5 & 9.1 & 9.6 & 10.2 & 10.7 \\
\hline $\mathrm{Na}_{2} \mathrm{O}$ & 1.0 & 21.0 & 19.0 & 17.0 & 15.0 & 13.0 & 11.0 \\
\hline $\mathrm{CaO}$ & 40.0 & & 4.0 & 8.0 & 12.0 & 16.0 & 20.0 \\
\hline $\mathrm{Fe}_{2} \mathrm{O}_{3}$ & 8.0 & & 0.8 & 1.6 & 2.4 & 3.2 & 4.0 \\
\hline $\mathrm{SO}_{3}$ & 4.5 & & 0.45 & 0.90 & 1.35 & 1.80 & 2.25 \\
\hline $\mathrm{TiO}_{2}$ & 3.0 & & 0.30 & 0.60 & 0.90 & 1.20 & 1.5 \\
\hline $\mathrm{P}_{2} \mathrm{O}_{5}$ & 2.6 & & 0.26 & 0.52 & 0.78 & 1.04 & 1.3 \\
\hline $\mathrm{Cr}_{2} \mathrm{O}_{3}$ & 1.0 & & 0.10 & 0.20 & 0.30 & 0.40 & 0.5 \\
\hline Others & 4.2 & & 0.49 & 0.88 & 1.27 & 1.66 & 2.15 \\
\hline
\end{tabular}

\section{Experimental}

The chemical composition of the base borosilicate glass applied in experiment was $\mathrm{SiO}_{2}-56.0, \mathrm{~B}_{2} \mathrm{O}_{3}-15.0, \mathrm{Al}_{2} \mathrm{O}_{3^{-}}$ 8.0, and $\mathrm{Na}_{2} \mathrm{O}-21.0$ mass \%.

The glass was obtained by melting of batch composed of quartz sand, $\mathrm{Na}_{2} \mathrm{CO}_{3}$, boric acid, and aluminum oxide of chemical grade purity. Then was melted at $1473 \mathrm{~K}$ for $2 \mathrm{~h}$ in an alumina crucible, cooled, and crushed into $0.3-0.1 \mathrm{~mm}$ grain size.

The obtained glass frit was mixed with ash from hospital waste incineration plant in Krakow (Poland). The mixtures were melted at $1473 \mathrm{~K}$ for $2 \mathrm{~h}$ in an alumina crucible and vitrified. The glass to the ash ratio was $10,20,30,40$, and 50 mass $\%$ and samples were designated BS10W, BS20W, BS30W, BS40W, and BS50W, respectively. The chemical composition of the ash, glass, and vitrified product is presented in Table 1.

Heating microscopy thermal analysis was carried out using compacted powder samples of cubic shape. Powdered samples prepared by milling of bulk samples in a ball mill were wetted in ethanol and compacted to cubes of $3 \times 3 \times 3 \mathrm{~mm}$ by a hand press. The changing of the samples' shape was conducted by Carls Zeiss MH01 microscope at heating rate $8 \mathrm{~K} \mathrm{~min}^{-1}$. Data of the sample height were collected at intervals of $10 \mathrm{~K}$ during the experiment, and shrinkage curves were obtained. The beginning of sintering process temperature $T_{\mathrm{s}}$ as the onset of densification was determined from the shrinkage curve. The half sphere temperature $T_{\mathrm{hs}}$ which was the temperature at which the height of the sample was half the width of the base, the flow temperature $T_{\mathrm{f}}$ which was the first temperature at which the sample was melted to a third of its original height were observed.

Glass transformation $T_{\mathrm{g}}$ at the half of the specific heat capacity change step, crystallization $T_{\mathrm{C}}$ as the onset of the first crystallization peak and melting $T_{\mathrm{m}}$ as the onset of the first melting peak temperatures were measured by differential scanning calorimetry (DSC) method at the heating rate $7 \mathrm{~K} \mathrm{~min}^{-1}$. Measurements were carried out using Perkin Elmer DTA/DSC-7 heat flow differential scanning calorimeter. Pure $\mathrm{Al}$ and $\mathrm{Au}$ were used for temperature and heat calibration. Value of specific heat capacity change $\Delta C_{\mathrm{p}}\left(\mathrm{J} \mathrm{g}^{-1} \mathrm{~K}^{-1}\right)$, accompanying glass transformation was determined using Perkin Elmer Pyris Thermal Analysis Software Library program.

\section{Results and discussion}

The shrinkage curve of the base borosilicate glass is presented in Fig. 1. Between 880 and $1000 \mathrm{~K}$ the first shrinkage is observed. In this region sample dimensions decrease, but the shape remains unchanged. This is the sintering stage $\left(T_{\mathrm{s}}=911 \mathrm{~K}\right)$. Over $1000 \mathrm{~K}$ the sintering process is finished the maximum of densification is achieved and observed a plateau on the curve. The sample dimension persists unchanged. As the temperature increases the liquid phase appears on the surface of the sample which is observed as a smoothing and rounding of the corners (about $1050 \mathrm{~K}$ ). Beyond this point the sample starts to behave like a liquid, begins the melting process, its viscosity decreases with temperature, a round sphere shape is formed, and the second shrinkage step on the curve (Fig. 1) is observed. The specimen shape becomes first spherical than semispherical $\left(T_{\mathrm{hs}}=1133 \mathrm{~K}\right)$ until final melting point, the flow temperature $\left(T_{\mathrm{f}}=1200 \mathrm{~K}\right)$ is achieved. All the investigated samples behave in the same manner with the short plateau on the shrinkage curve and melting like a typical glass (exhibits spherical shapes) what is the evidence of their low crystallization ability. The sintering, half sphere, and flow temperatures of the examined materials are presented in Table 2 . 


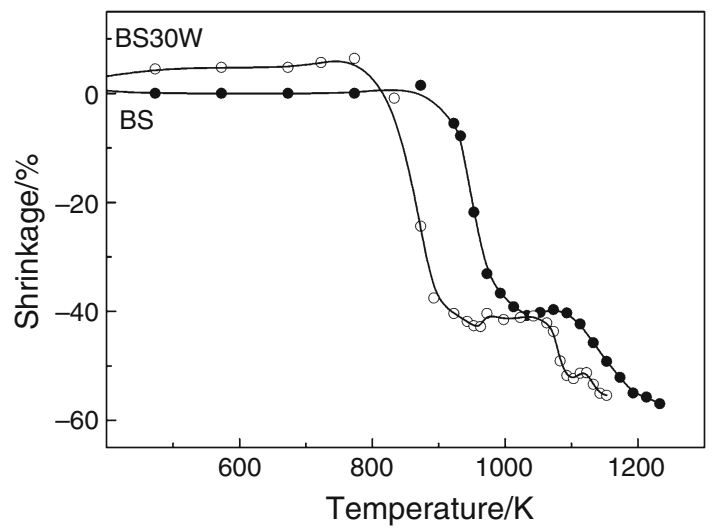

Fig. 1 Shrinkage curves of the BS and BS30W samples

Table 2 The sintering $\left(T_{\mathrm{s}} / \mathrm{K}\right)$, half sphere $\left(T_{\mathrm{hs}} / \mathrm{K}\right)$ and flow $\left(T_{\mathrm{f}} / \mathrm{K}\right)$ temperatures

\begin{tabular}{llll}
\hline Sample & $T_{\mathrm{s}} / \mathrm{K}$ & $T_{\mathrm{hs}} / \mathrm{K}$ & $T_{\mathrm{f}} / \mathrm{K}$ \\
\hline BS & $911(5)$ & $1130(5)$ & $1200(5)$ \\
BS10W & $906(5)$ & $1050(5)$ & $1130(5)$ \\
BS20W & $889(5)$ & $1040(5)$ & $1110(5)$ \\
BS30W & $887(5)$ & $1070(5)$ & $1150(5)$ \\
BS40W & $889(5)$ & $1070(5)$ & $1150(5)$ \\
BS50W & $898(5)$ & $1060(5)$ & $1150(5)$ \\
\hline
\end{tabular}

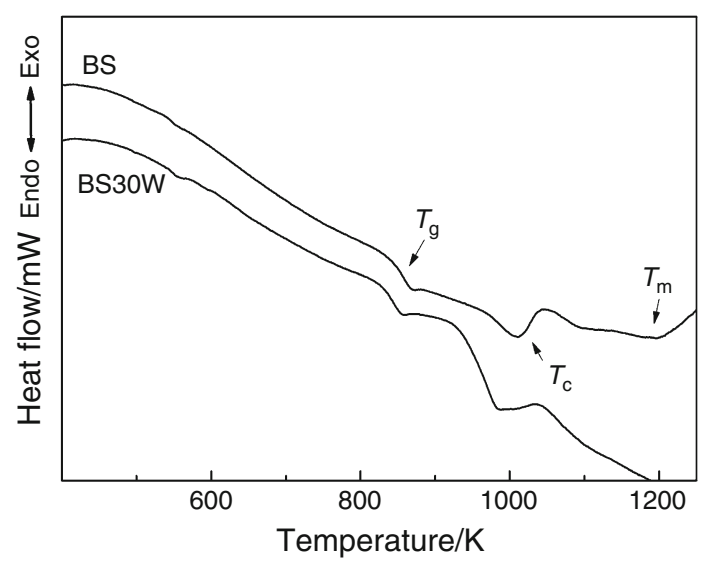

Fig. 2 DSC curves of the BS and BS30W samples

The sintering temperature is slightly reduced from above $900 \mathrm{~K}$ to about $890 \mathrm{~K}$ when the ash is added up to 20 mass $\%$ quantities and for higher waste concentrations the temperature is almost constant. In the similar way behave both $T_{\mathrm{hs}}$ and $T_{\mathrm{f}}$-temperatures.

The effect of addition of ash to the $\mathrm{Na}_{2} \mathrm{O}-\mathrm{B}_{2} \mathrm{O}_{3}-\mathrm{Al}_{2} \mathrm{O}_{3}-$ $\mathrm{SiO}_{2}$ glass on its thermochemical properties is demonstrated by the DSC curves. An exemplary DSC curve for the base glass is presented in Fig. 2. The glass shows a broad effect on the plateau above the transformation step,
Table 3 The transformation $\left(T_{\mathrm{p}} / \mathrm{K}\right)$, crystallization $\left(T_{\mathrm{c}} / \mathrm{K}\right)$, melting $\left(T_{\mathrm{m}} / \mathrm{K}\right)$ temperatures, $\left(\Delta C_{\mathrm{P}} / \mathrm{J} \mathrm{g}^{-1} \mathrm{~K}^{-1}\right)$, Hruby's parameter $\left(K_{\mathrm{H}}\right)$

\begin{tabular}{llrlll}
\hline Sample & $T_{\mathrm{g}} / \mathrm{K}$ & \multicolumn{1}{c}{$T_{\mathrm{C}} / \mathrm{K}$} & \multicolumn{1}{l}{$T_{\mathrm{m}} / \mathrm{K}$} & $\Delta C_{\mathrm{P}} / \mathrm{J} \mathrm{g}^{-1} \mathrm{~K}^{-1}$ & $K_{\mathrm{H}}$ \\
\hline BS & $858(5)$ & $1028(5)$ & $1163(5)$ & $0.26(2)$ & 1.26 \\
BS10W & $846(5)$ & $1007(5)$ & $1166(5)$ & $0.27(2)$ & 1.01 \\
BS20W & $842(5)$ & $995(5)$ & $1174(5)$ & $0.36(2)$ & 0.85 \\
BS30W & $840(5)$ & $995(5)$ & $1179(5)$ & $0.32(2)$ & 0.84 \\
BS40W & $835(5)$ & $995(5)$ & $1193(5)$ & $0.41(2)$ & 0.80 \\
BS50W & $838(5)$ & $997(5)$ & $1189(5)$ & $0.38(2)$ & 0.82 \\
\hline
\end{tabular}

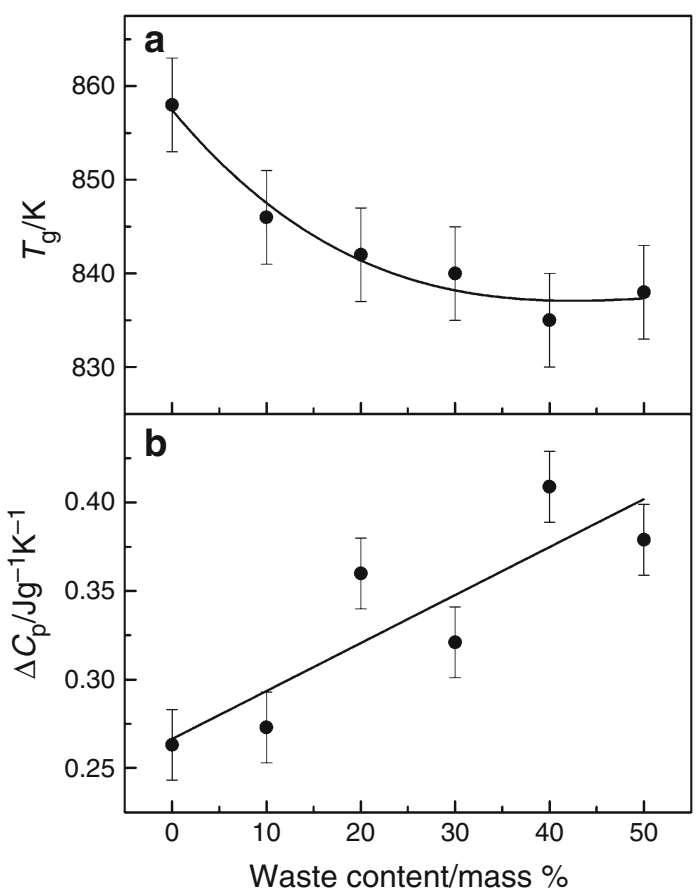

Fig. 3 Transformation temperature $T_{\mathrm{g}}$ (a) and the specific heat capacity $\Delta C_{\mathrm{p}}$ accompanying the glass transformation (b) as the waste content function

which is indication of the low degree of chemical homogeneity of the glass. Just behind there appears a poor effect of crystallization and then melting process occurs. The similar curves are observed for the rest of the measured samples. The obtained transformation, crystallization, and melting temperatures for all of the investigated materials are presented in Table 3 .

Influence of the ash content on transformation temperature $T_{\mathrm{g}}$ is presented in Fig. 3a. The $T_{\mathrm{g}}$-temperature is reduced with the ash addition. According to previous studies [6] this effect should not be connected only with replacing $\mathrm{Na}_{2} \mathrm{O}$ by $\mathrm{CaO}$, which is the main ash component in the glass structure. On the other hand, addition of the ash to the glass is causing decrease of the number of network forming cations which leads to reduction of the directional covalent bonds and at the same time increase the 


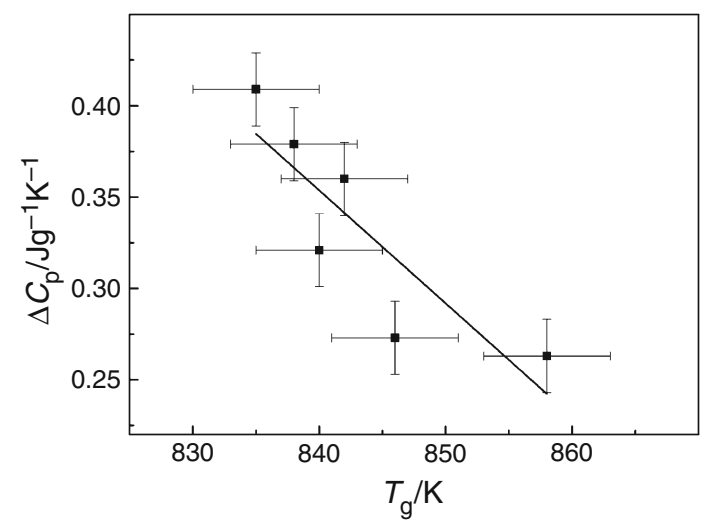

Fig. 4 Specific heat capacity change $\Delta C_{\mathrm{p}}$ as the transformation temperature $T_{\mathrm{g}}$ function

proportion of ionic bonds and broken network oxide bridges. On the other hand increasing number of ionic bonds indicate that the structure becomes more flexible, cations could move easier and decomposition of the structure could take place in a lower temperatures leading to reduction of the $T_{\mathrm{g}}$ [7].

The ash increases the change of the specific heat capacity $\Delta C_{\mathrm{p}}$ accompanying the glass transformation.

(Fig. 3b), the value of which can be the index of the degree of structural changes accompanying the transformation (number and force of the broken bonds, components rearrangement). As was previously observed [7, 8] change of the modifier cation e.g., replacement of sodium by calcium is connected with increase of the $\Delta C_{\mathrm{p}}$ value which forms a less ionic bonds with oxygen than sodium.

DSC curve with its coordinate $\mathrm{d} H / \mathrm{d} T$, and $T(t)$ where $H$-enthalpy, $T$-temperature and $t$-time, makes possible to measure $\Delta C_{\mathrm{p}} \mathrm{Jg}^{-1} \mathrm{~K}^{-1}$ at $T_{\mathrm{g}}$ temperature accompanying the glass transformation, it is transition from glass as solid body to its visco-elsatic state at $T_{\mathrm{g}}$ temperature. It can be used as an indicator of the configuration entropy change connected with degree of the glass structure rebuilding at $T_{\mathrm{g}}$ temperature and its energetic measure supplementing the molar volume $\Delta V \mathrm{~cm}^{3} \mathrm{~mol}^{-1}$ and viscosity change as the internal structure rebuilding characteristics $[8,9]$. Usefulness of the $\Delta C_{\mathrm{p}}$ of glass transition in the structural consideration was confirmed several times [7, 10].

As was mentioned above introduction of the ash to the glass structure reduces the number of covalent bonds. These bonds because of its directional nature could lead to higher internal structural strains. The strains may cause the cracking of the bonds, what is less probable in the case of bonds of high ionicity. More the internal strain the higher energy is accumulated in the glass network and lower energy is needed to break the bonds at the glass transition temperature. It is supported by the fact that the transition of a pure silicate glasses take place with the very small

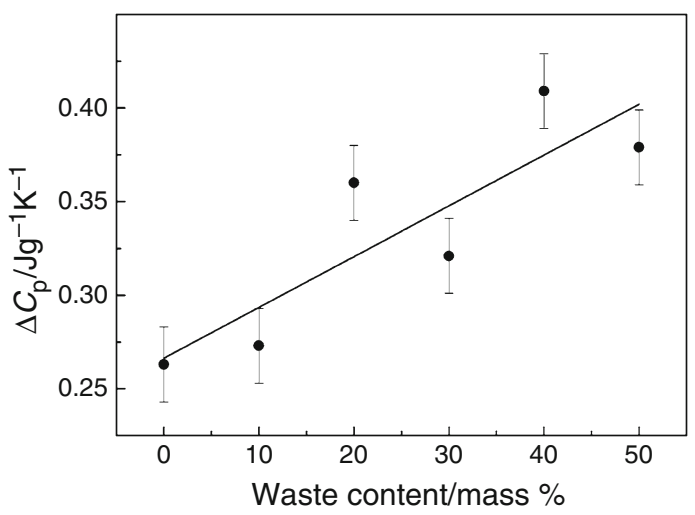

Fig. 5 The Hruby parameter $K_{\mathrm{H}}$ as the waste content function

change in $C_{\mathrm{p}}$ [8]. Thus increase in $\Delta C_{\mathrm{p}}$ with the ash (modifiers) concentration is observed (Fig. 3b).

It is interesting to notice in case of the investigated glasses exist a relation between the glass transition temperature $T_{\mathrm{g}}$ and the specific heat capacity change $\Delta C_{\mathrm{p}}$ accompanying this transition (Fig. 4). The lower $T_{\mathrm{g}}$ temperature and higher the $\Delta C_{\mathrm{p}}$ value is the case with the high concentration of the glass network modifiers and more elastic ionic bonds, less rigid covalent bonds and less the internal strains it means more flexible the glass structure. The higher flexibility gives possibility to move the cations at lower temperatures and bending the whole glass structure and because of the lower internal energy the higher energy should be set to break the covalent bonds leading to the higher $\Delta C_{\mathrm{p}}$.

One of the important parameter in case of waste vitrification is a thermal stability of the vitrified product. The glass stability of the investigated materials was evaluated using Hruby criterion. According to [11] the higher $K_{\mathrm{H}}$ value the greater would be its stability against crystallization. The $K_{\mathrm{H}}$ value was evaluated according to the formulae:

$K_{\mathrm{H}}=\frac{T_{\mathrm{c}}-T_{\mathrm{g}}}{T_{\mathrm{m}}-T_{\mathrm{c}}}$

The obtained $K_{\mathrm{H}}$ parameters are summarized in Table 3 and Fig. 5.

All of the investigated glasses evidenced high glass stability with the $K_{\mathrm{H}}$ parameter over 0.8 . The values of $K_{\mathrm{H}}$ parameters for silicate glasses varied from 0.14 to about 1.3 [12-14]. The increasing of the ash concentration is causing decrease of the $K_{\mathrm{H}}$ parameter and thus it lowers the glass stability against crystallization on heating and in the same way the glass ability to vitrify on cooling [14].

The existence of a relation between $\Delta C_{p}$ and the ability of a glass to crystallize was observed previously [8]. Glasses crystallizing easily are characterized by a greater value of $\Delta C_{\mathrm{p}}$ as compared with glasses that crystallize with 


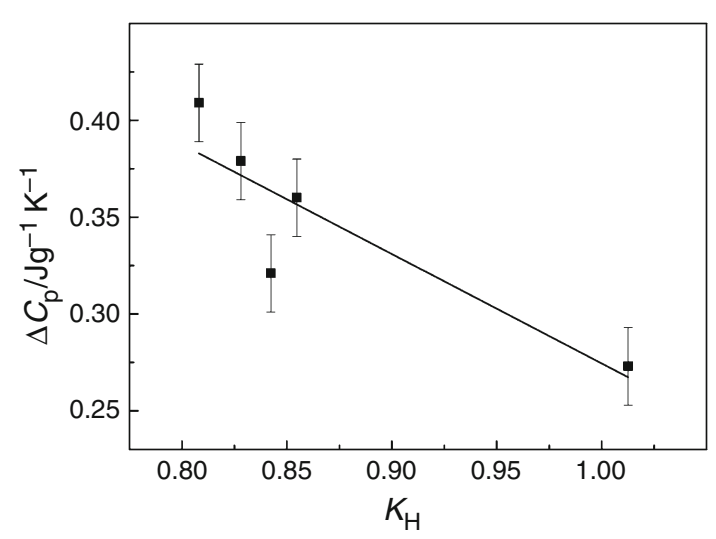

Fig. 6 Dependence of specific heat capacity change $\Delta C_{\mathrm{p}}$ versus the $K_{\mathrm{H}}$ parameter

difficulty. As the $\Delta C_{\mathrm{p}}$ and the $K_{\mathrm{H}}$ parameter could describe glass stability against crystallization there should exist relation between them. Such the relation is presented in Fig. 6 . As can be clearly seen the higher $\Delta C_{\mathrm{p}}$ value means lower glass structure stability its deeper destruction at the $T_{\mathrm{g}}$ temperature and in the same way the lower the $K_{\mathrm{H}}$ parameter. That proves the $\Delta C_{\mathrm{p}}$ value obtained by DSC method could be also used as glass stability against crystallization parameter. The $\Delta C_{\mathrm{p}}$ value is related to the change of entropy accompanying glass transition and considered as the structure modification degree indicator [9].

\section{Conclusions}

The conventional borosilicate waste glass was used to vitrify ashes from a hospital waste incineration plant. The influence of the ash addition on thermal properties of the obtained materials was investigated. The addition of the ash is causing only slightly reduction of the all characteristic temperatures like sintering, transformation, crystallization, and melting. On the other hand increases the $\Delta C_{\mathrm{p}}$ which is correlated with the glass transition temperature $T_{\mathrm{g}}$ and glass stability $K_{\mathrm{H}}$ parameter. The ash constituents increase elasticity of the glass structure and thus reduce $T_{\mathrm{g}}$ and decrease stability of the product against crystallization on heating. Nevertheless, the thermal stability of proposed glass containing even considerable quantities of the ash is good, which makes the proposed glass suitable to vitrify such a waste.
Acknowledgements The work was supported by The National Centre for Research and Development of Poland as a part of strategic research project Technologies Supporting Development of Safe Nuclear Energy.

Open Access This article is distributed under the terms of the Creative Commons Attribution License which permits any use, distribution, and reproduction in any medium, provided the original author(s) and the source are credited.

\section{References}

1. Donald W. Immobilisation of radioactive and non-radioactive wastes in glass-based systems: an overview. Glass Technol. 2007; 48:155-63.

2. Ojovan MI, Lee WE. An introduction to nuclear waste immobilisation. Amsterdam: Elsevier Science publishers B.V; 2005. p. 315 .

3. Sobolev IA, Dmitriev SA, Lifanov FA, Kobelev AP, Stefanovsky SV, Ojovan MI. Vitrification processes for low, intermediate radioactive and mixed wastes. Glass Technol. 2005;46:28-35.

4. Choi K, Sheng J, Lee MC, Song MJ. Utilizing the KEP-A glass frit to vitrify low-level radioactive waste from Korean NPPs. Waste Manag. 2000;20:575-80.

5. Juoi JM, Ojovan MI. The effect of waste loading on the microstructure of glass composite waste form immobilising spent clinoptilolite. Glass Technol. 2007;48:124-9.

6. Stoch P. Cs containing borosilicate waste glasses. Opt Appl. 2008;38:237-43.

7. Stoch L, Wacławska I, Środa M. Thermal study of the influence of chemical bond iconicity on the glass transformation in $\left(\mathrm{Na}_{2} \mathrm{O}\right.$, $\mathrm{CaO}, \mathrm{MgO})-\mathrm{Al}_{2} \mathrm{O}_{3}-\mathrm{SiO}_{2}$ glasses. J Therm Anal Cal. 2004;77: 57-63.

8. Stoch L. Termochemistry of solids with flexible structures. J Therm Anal Cal. 1998;54:9-24.

9. Stoch L. Thermal analysis and termochemistry of vitreous to crystalline state transition. J Therm Anal Cal. 2004;77:7-16.

10. Wacławska I, Sroda M, Stoch L. Thermal methods applied to the glass transition of mixed network $\mathrm{AlPO}_{4}-\mathrm{BPO}_{4}-\mathrm{SiO}_{2}$ glasses. J Therm Anal Cal. 2001;65:661-7.

11. Hruby A. Evaluation of glass-forming tendency by means of DTA. Czech J Phys B. 1972;22:1187-96.

12. Cabral AA, Cardoso AAD, Zanotto ED. Glass-forming ability versus stability of silicate glasses I. Experimental test. J NonCryst Solids. 2003;320:1-8.

13. Lin SE, Cheng YR, Wei WCJ. Synthesis and long-term test of borosilicate-based sealing glass for solid oxide fuel cells. J Eur Ceram Soc. 2011;31:1975-85.

14. Nascimento MLF, Souza LA, Ferreira EB, Zanotto ED. Can glass stability parameters infer glass forming ability? J Non-Cryst Solids. 2005;351:3296-308. 